Artigos 


\section{Orfani italiani no Juízo dos Órfãos de Porto Alegre (final do século XIX)*}

José Carlos da Silva Cardozo*

Resumo: Muitas crianças e adolescentes italianos, juntamente com seus familiares, transpuseram as barreiras oceânicas e vieram para o Rio Grande do Sul em busca de melhores oportunidades de trabalho e condições de vida. Contudo, as vicissitudes que cercavam a maioria da população, entre o final do século XIX e início do XX, também afligiram as famílias dos imigrantes italianos, em algumas das quais foram completamente desarticuladas devido ao falecimento de seus genitores. Assim, muitas crianças e adolescentes imigrantes ou descendentes tiveram que conviver também com a orfandade. Para cuidar dessas crianças, o Estado brasileiro possuía o Juízo dos Órfãos, instituição do Judiciário destinada a atribuir um adulto como responsável legal pelo menor, e o governo italiano uma instância de representação legal no Brasil - o Consulado Italiano. É a intenção deste trabalho, por meio da História Social, apresentar alguns dos pequenos italianos e ítalo-brasileiros que tiveram suas histórias registradas nos Processos de Tutela da cidade de Porto Alegre, os quais receberam atenção do Consulado Italiano de Porto Alegre em suas ações. Dessa forma, refletir sobre esses menores estrangeiros e trazer para análise as crianças e os adolescentes que, muitas vezes, ficam em segundo plano nos estudos e/imigratórios.

Palavras-chave: Órfãos. Estrangeiros. Italianos. Juízo dos Órfãos.

\footnotetext{
*À memória de minha mãe, Cecília Tereza Deves.

** Doutorando em História Latino-Americana (UNISINOS). Professor concursado da Secretaria de Educação do RS. Editor da Revista Latino-Americana de História e da Revista Brasileira de História \& Ciências Sociais. Secretário da Anpuh/RS. Bolsista Capes/MEC. E-mail: jcs.cardozo@gmail.com.
} 


\section{Introdução}

Fazer a América. Quantas vezes essa frase embalou sonhos e corações no Velho Continente. Homens, mulheres e crianças de todas as idades e etnias viram-se atraídos pelas possibilidades que o Novo Mundo estava a ecoar numa Europa cada vez mais assolada por fome, doenças e epidemias. Fazer a América significava trabalhar, mas, ao mesmo tempo, sonhar com uma vida feliz. O sentimento de esperança inspirava a todos nos anos finais do século XIX e início do XX.

Emigrar foi uma alternativa real para a sobrevivência de muitos. No início, ela era temporária, ocorrendo para uma região ou mesmo para fora do país, mas dificilmente para fora do continente. No entanto, devido não só às circunstâncias estruturais como a expropriação dos camponeses, na agricultura, e dos artesãos, nas cidades, mas também ao aumento da densidade demografia, que acarretava a falta de alimentos e de trabalho, acabava tornando-se dificultosa a permanência de muitos na Europa (GIRON, 1980; SANTOS, 1980; FAVARO, 2006). Fugir da macabra equação fome-doença-epidemia-fome era uma questão de sobrevivência.

Buscando novas possibilidades de renda e sobrevivência, as famílias Marine (ou Marini) e Sigandi juntaram-se a mais de 84 mil italianos que empreenderam a aventura de cruzar o oceano Atlântico, partindo da península itálica para a região mais meridional do Brasil, entre 1875 e 1914. Dessa forma, apresentaremos a participação do Consulado Italiano no Juízo dos Órfãos de Porto Alegre em ações judiciais que envolveram menores de idade de origem ou descendência italiana que tiveram que lidar com a vicissitude da orfandade. Consulado que mesmo não tendo deixado registrado em seus "relatórios consulares" (IOTTI, 2001), depreendeu a atenção para com o bem-estar das crianças e dos adolescentes italianos ou ítalo-brasileiros.

O estado unitário italiano foi um processo de construção político-econômico-social desenvolvido ao longo do século XIX, sendo a emigração um dos temas latentes. Até a década de 70 e o início dos anos 80, o Reino da Itália via a emigração como um problema, pois compreendia, entendimento advindo dos latifundiários, que a saída de homens e mulheres da Itália reduziria a oferta de mão de obra, 
provocando o aumento nos salários pagos e, consequentemente, aumento nos gastos com a produção.

Contudo, no final da década de 80, o Estado italiano inicia um processo de reformas, atingindo também o Ministério dos Negócios Exteriores, ministério responsável pelos diplomatas e pelas representações diplomáticas do Reino da Itália ao redor do mundo. A partir desse período "[...] houve uma mudança significativa na atitude do Estado italiano diante do processo emigratório. A emigração começou a ser vista como parte do mercado internacional, estabelecendo-se a equação 'mais emigrantes, mais comércio" (IOT'TI, 2001, p. 52). Dentro dessa nova perspectiva, os consulados deveriam não só estar atentos a questões políticas, mas também jurídicas, pois deveriam acompanhar os emigrantes na nova terra. O estado italiano e os grupos dirigentes inverteram a postura em perceber o emigrante como um problema para ver nele uma solução, pois esse consumiria produtos italianos no exterior e remeteria seus ganhos para seu país de origem. O Reino da Itália recuava em favorecer ao grupo dos latifundiários para beneficiar os comerciantes e os industrialistas.

Mudança que se mostrara frutífera, pois, nas palavras de um funcionário do ministério da agricultura contemporâneo ao processo, o Comendador Antonio Monzili,

[...] a emigração tem sido extremamente útil ao nosso país; ela tem contribuído para o progresso econômico, seja diminuindo a população [...], seja aumentando a riqueza capitalista italiana através da poupança arrecadada com o trabalho no exterior (apud IOT'TI, 2001, p. 56).

Contudo, Luiza Iotti (2001) estudando os relatórios consulares do final do século XIX e início do século XX, remetidos do Rio Grande do Sul para a Itália, identificou neles a presença pejorativa dos valores dos grupos dirigentes em relação ao emigrante italiano no Brasil. Os relatórios estudados revelaram o interesse econômico e elitista por parte dos cônsules.

Dessa forma, afastando-nos dos documentos oficiais do Ministério dos Negócios Exteriores do Estado italiano, buscaremos refletir sobre a participação do Consulado Italiano de Porto Alegre em rela- 
ção à família de origem ou descendência italiana, no final do século XIX. História que não será contada por documentos tendo por personagens os adultos, mas, sim, pelos registros dos pequenos membros das famílias Marine e Sigandi: as crianças e os adolescentes que, muitas vezes, ficam em segundo plano nos estudos e/imigratórios.

\section{Crianças e adolescentes e/imigrantes - um estudo possível}

Não é fácil a tarefa daquele que deseja estudar a e/imigração tendo por foco a participação dos menores de idade. Os estudos concentram-se mais na atuação dos adultos, segregando uma importante parcela dos que ajudaram na manutenção da família, ou que tiveram participação intensa na sociedade, seja em atividades ligadas à agricultura, na nascente indústria ou nas atividades domésticas. É significativo perceber que temas relacionando menores de idade e e/imigração estejam, na maioria das vezes, relacionados ao mundo do trabalho, como o trabalho de Esmeralda Moura (1982) para a cidade de São Paulo e de Ramon Tisott (2008) para Caxias do Sul.

Uma das muitas dificuldades em se estudar a história da criança e/imigrante

[...] é a falta de informações em fontes documentais sobre imigração que, em geral, são reticentes no que se refere ao cotidiano dessa criança, à sua vivência no universo familiar, ao seu dia-a-dia na escola, às suas brincadeiras em casa e na rua ou, ainda, aos momentos de angústia e desamparo, causados pela desestruturação da família (SCOT'T; BASSANEZI, 2005, p. 163).

Ana Scott e Maria Bassanezi (2005) chamam a atenção para o "silêncio" das fontes sobre a criança e/imigrante, o que advém, provavelmente, dos "produtores dos documentos", que tinham atenção especial para o trabalhador em potencial, ficando as crianças legadas ao último plano pelas autoridades estatais, pelos agentes de imigração ou mesmo empregadores. 
Mas a curiosidade é o grande motivador do Historiador: o que seria dos estudos relativos à escravidão no Brasil se os historiadores tivessem se dado por satisfeitos com o fato de Rui Barbosa ter mandado queimar "todos" os registros da escravidão no país? Pesquisa, leitura e criatividade, juntamente com um pouco de sorte, são fatores que ampliam o campo das possibilidades na pesquisa histórica. As palavras de Marc Bloch continuam vivas e servindo de inspiração para a curiosidade do historiador quando ele afirma que "[...] o bom historiador se parece com o ogro da lenda. Onde fareja carne humana, sabe que ali está sua caça” (BLOCH, 2001, p. 54).

Dessa forma, farejando crianças e adolescentes nos arquivos empoeirados da cidade de Porto Alegre, fomos contemplados com nossa caşa - o Juízo dos Órfãos ${ }^{1}$.

\section{Juízo dos Órfãos}

O Juízo dos Órfãos foi uma instituição jurídica que teve sua origem em Portugal, remontando ao século XV. A criação desse Juizado deveu-se à necessidade de definir normas que regulamentassem a proteção dos menores de 25 anos de idade ${ }^{2}$, no que competia não só à administração própria, mas também à de seus bens. O cuidado e a administração do órfão, por parte de um adulto legalmente constituído, eram necessários, em vista dos processos de separação de bens (partilha) ou mesmo de herança, em virtude de falecimento do pai do menor. Numa contingência desse tipo, o adulto ficaria responsável por representar os interesses do menor nesse processo, que, em certas circunstâncias, poderia se transformar numa ação que desembocasse em litígio $^{3}$. A necessidade de um adulto como responsável por um menor também poderia vir pela orfandade completa. Assim, o Juízo dos Órfãos deteve suas atenções nos menores de idade que possuíssem bens ou fossem descendentes de família de posse e/ou de prestígio social.

O Juizado de Órfãos, como também era chamado, foi igualmente instalado na colônia portuguesa na América e, com o aumento da população na colônia, foi regulamentado, em maio de 1731, o cargo de Juiz de Órfãos no Brasil. Em Porto Alegre, esse 
cargo foi criado em 26 de janeiro de 1806, teve sua reorganização administrativa em 1927, com o Código de Menores, e sua completa reformulação das atividades em 1933, ano em que foi criado o Juizado de Menores pela Intendência Municipal. Nesse percurso, a partir de 1850, a instituição foi direcionando sua atenção também

( para os menores não pertencentes às elites; com uma nova ética do trabalho sendo introjetada pelos grupos dirigentes no Brasil, a sociedade deveria cuidar das crianças e dos adolescentes, pois eles eram compreendidos como o futuro da nação e não deveriam ser criados em meios perniciosos ou viciados. Assim, o Estado brasileiro, por meio do Juízo dos Órfãos, agiu de forma eficiente para proteger os menores de idade dos perigos que responsáveis negligentes poderiam trazer para sua formação como cidadãos.

Dessa forma, o Juízo de Órfãos era o tribunal em que se tratava de tudo que dizia respeito a um menor de idade, ou a pessoas incapacitadas, como os pródigos (pessoas que gastam seu capital ou destroem seus bens; Ord. Fil. liv. 4ª tit. 103 \$6), os furiosos (pessoas com as faculdades mentais debilitadas; Ord. Fil. liv. $4^{\mathrm{a}}$, tit. 103), os doentes graves (pessoas impossibilitadas de administrar seus bens) e os indígenas (Ord. Fil. liv. $1^{\circ}$, tit. 88). Pela forma da lei vigente, essas pessoas, embora atingissem a maioridade legal, necessitavam de um adulto legalmente constituído por esse Juízo (o curador) como seu representante e responsável ${ }^{4}$.

Portanto, essa instituição, vinculada ao Poder Judiciário ${ }^{5}$ que tinha por objetivo cuidar e zelar de todos os menores de idade que estavam sob sua jurisdição -, produziu muitos processos judiciais que atualmente se tornam fontes privilegiadas para visualizar a criança e o adolescente na sociedade brasileira, possibilitando perceber crianças, adolescentes e jovens inseridos tanto nas relações familiares quanto na relação com os operadores do direito. Sem fazer distinção, todos os menores de idade que porventura enfrentassem algum problema relacionado ao seu responsável, ou à falta dele, eram encaminhados ao Juízo dos Órfãos ${ }^{6}$.

A documentação típica desse fundo compõe-se de processos de variada complexidade e tipologia e sua análise oferece uma visão sobre o cotidiano da criança, da família e das 
relações que se estabeleciam entre os adultos e as crianças em situação de crise (SCOTT'; BASSANEZI, 2005, p. 169).

Privilegiamos neste texto apenas dois Processos de Tutela abertos no final do século XIX, entre muitos, por estes apresentarem a ação direta do Estado italiano, por meio de seu Consulado na cidade de Porto Alegre, no destino das famílias e das crianças e dos adolescentes. Os autos de tutela tinham por objetivo dar um tutor para um menor de idade que se encontrasse em situação de vulnerabilidade. $\mathrm{O}$ cargo de tutor era de função jurídico-social, com alto grau de responsabilidade, pois tudo que dissesse respeito ao menor seria de sua alçada, devendo aquele responder pelas ações das crianças e dos adolescentes, tanto em Juízo quanto fora dele. O cargo era conferido pelo Juiz de Órfãos a uma pessoa para que gerenciasse os bens e cuidasse da integridade física de um menor de idade, quando uma criança era órfã de pai ou quando este fosse ausente, vagabundo ou dado a vícios. Nesses casos, o Juiz de Órfãos nomeava um tutor para cuidar da criança, exceto quando não houvesse algum nome indicado em testamento. Isso acontecia mesmo que o menor tivesse mãe ou vivesse com ela, pois esta era, geralmente, considerada impedida de assumir a responsabilidade jurídica de seus filhos se tivesse que trabalhar na via pública ou se casasse novamente.

Dessa forma, refletir sobre a ação do Consulado Italiano em Porto Alegre, por meio dos processos de tutela de menores de idade, revela algo que a historiografia sobre a e/imigração ainda não tinha se detido: o cuidado que o Consulado Italiano tinha para com os membros menores das famílias de origem ou descendência italiana no Brasil.

\section{A família Marini}

Stephano Marini (ou Stefano Marini) veio para o Rio Grande do Sul com a esperança de ter uma nova vida. Deixara para trás o Reino da Itália para trabalhar no país da fartura, como os Estados e os agentes da imigração descreviam o Brasil. Contudo, sua esposa faleceu, deixando a menor Maria Marini ${ }^{7}$ (ou Marine) sem a mãe. O pai 
casou-se novamente, mas veio a falecer, em São João de Montenegro, em fevereiro de 1899. Dessa forma, a menor ficaria com a viúva de seu pai, sua madrasta.

Porém, no dia 10 de abril do mesmo ano, o senhor Luiz Candido de Albuquerque, casado e comerciante da cidade de Porto Alegre, entrou com um pedido de tutela no Juízo dos Órfãos de Porto Alegre, solicitando a guarda da menina. Para isso, informava que "[...] há quatorze meses acha-se em sua companhia a menor Maria Marine", que contava com onze anos de idade. Ora, o que teria levado esse senhor a abrir um processo judicial requerendo a tutela da menor Maria, uma vez que sua madrasta, que morava em São João de Montenegro, ficaria com ela? Antes disso, o que a menor fazia havia quatorze meses na casa de Luiz Candido?

Como a renda familiar era complementada pelos esforços de crianças e adolescentes, Stephano Marini empregou sua filha na casa do senhor Albuquerque, pois necessitava de auxílio financeiro para incrementar a produção de sua pequena plantação em São João de Montenegro. Mas, o que motivou o empregador a pedir a tutela da menor? Com a morte do pai, a madrasta queria "receber a quantia mensal” (RIO GRANDE DO SUL, 1899, s. p.) - o salário da menina - que era paga ao seu falecido marido pelo trabalho de Maria Marini.

Luiz Candido pediu a tutela da menor alegando que "[...] o produto do trabalho dessa menor não deve ser explorado [...]" (RIO GRANDE DO SUL, 1899, s. p.) pela madrasta, o que garantia, por fim, que o dinheiro que a menor ganhasse pelo seu "produto mensal" seria depositado na Caixa Econômica.

Com o processo em mãos, o Juiz de Órfãos Dr. Antonio Marinho Lourino Chaves manda, então, que "[...] seja apresentada a este Juízo a menor órfã [...]” (RIO GRANDE DO SUL, 1899, s. p.) para esclarecimentos.

No dia quinze do mesmo mês, a menor Maria Marini compareceu na Sala de Audiências do Juízo dos Órfãos onde se achava o Juiz e o Escrivão Ruben Abbott. O Juiz perguntou à menor: "Qual seu nome, idade, se é órfã, com quem vive, como é tratada e onde quer permanecer?". Ela respondeu chamar-se Maria Marini, ter onze anos de idade e ser órfã de pai e mãe; acrescentou que vivia "[...] em companhia de Luiz Candido de Albuquerque, cidadão casado 
[...]”(RIO GRANDE DO SUL, 1899, s. p.) e que “[...] não é maltratada, pois lhe dão comida e roupa conquanto, às vezes, também lhe deem alguns tapas [...]" (RIO GRANDE DO SUL, 1899, s. p.), mas que "deseja continuar na companhia da família do senhor Albuquerque” (RIO GRANDE DO SUL, 1899, s. p.).

No mesmo dia, o Juiz pediu vistas ${ }^{8}$ do Dr. Curador Geral de Órfãos ${ }^{9}$, que respondeu "[...] não tenho razão para que me impilam a impugnar o pedido[...]” (RIO GRANDE DO SUL, 1899, s. p.) do suplicante a tutor da menor.

No dia vinte do mesmo mês, o Juiz do caso determina que

Nomeio o suplicante de fls. duas [pedido de tutela], cidadão Luiz Candido de Albuquerque tutor da menor Maria Marine. Lavre-se o respectivo termo de compromisso, no qual deve ser declarado a obrigação assumida pelo tutor de recolher mensalmente à Caixa Econômica a quantia de quinze mil reis em caderneta aberta em nome da menor. (RIO GRANDE DO SUL, 1899, s. p.)

O Juiz acolheu o pedido do senhor Luiz Candido Albuquerque, mas, desde que este deixasse ratificado, no Termo de Tutela e Compromisso do Tutor, que depositaria mensalmente a quantia estipulada como pagamento pelos serviços executados pela menor.

A Justiça percebia com bons olhos a colocação de menores de idade em atividades produtivas, pois elas colaborariam para a formação do caráter habituado ao trabalho e à responsabilidade, livrando os menores dos vícios e da vagabundagem (CARDOZO, 2009).

Dessa forma, não é de se estranhar que, em apenas cinco dias, a Justiça tenha concedido a guarda de uma menina para alguém fora do círculo parental. O Juízo dos Órfãos era um órgão eficiente já que, na maioria dos casos apresentados a ele, agia de forma rápida dando um responsável legal a um menor de idade que se encontrasse em situação de vulnerabilidade ou sem responsável (CARDOZO, 2011).

Contudo, o Reino da Itália não deixou seus súditos desamparados no território mais meridional do Brasil.

Luiza Iotti (2001) estudou a atuação dos Cônsules no Rio Grande do Sul e percebeu, por meio dos relatórios destes, entre 
1875 e 1914, a relação que o Reino tinha para com o país e seus emigrantes. Segundo a pesquisa da autora, os diplomatas percebiam os emigrantes como cidadãos de segunda classe, que deveriam ser acompanhados, pois poderiam naturalizar-se e, assim, renunciando à "pátria mãe", também renunciariam aos produtos fabricados lá. Havia uma visão elitista que guiava esses diplomatas que, não recebendo mesmo o prestígio que outras representações diplomáticas italianas ao redor do mundo, sendo considerados de "quadros inferiores" dentro dessa estrutura, eram oriundos de famílias da elite. Assim, os cônsules

[...] compartilhavam da mesma visão sobre a população pobre que havia sido obrigada a buscar fora do seu país as condições de vida que ele lhes negava. As relações que se estabeleceram entre eles e os imigrantes reproduziam, em parte, aquelas existentes, na Itália, antes da Imigração. O Estado italiano e seus representantes continuaram a agir, no Rio Grande do Sul, com a mesma indiferença, com o mesmo preconceito e desprezo que haviam manifestado pela população pobre que vivia na Itália (IOTTI, 2001, p. 83).

Mas, no caso da menor Maria Marini, não houve "indiferença": mesmo sendo ela pobre e órfã de pai e mãe, o Estado italiano agiu, por meio de seu consulado em Porto Alegre, com o propósito de levar a menina Maria de volta à sua terra natal.

No dia vinte de outubro, os autos voltam ao Juízo dos Órfãos, quando foi anexado ao processo o ofício do Cônsul italiano Enrico Ernesto Ciapelli, cônsul em Porto Alegre de 5 de dezembro de 1897 a 29 de janeiro de 1905, em papel timbrado do Consulado Real Italiano, redigido em italiano e dirigido ao "Presidente do Estado do Rio Grande do Sul", Dr. Antonio Augusto Borges de Medeiros, em que afirmava:

$\mathrm{O} \mathrm{R}^{\circ}$ Ministério dos Negocios do Exterior me ordena a providenciar afim de que volte à sua pátria a menor Maria Marini, filha de Stephano Marini falecido em São João de Montenegro em Fevereiro de 1899, para ser entregue a seu 
tio José Marini, nomeado tutor da dita menor pela Pretura Real de Tiene. A rapariga em questão se acha em casa do snr. Luiz Candido de Albuquerque tutor d'ela; nomeado pelo Juiz de Órfãos dessa cidade, e à mesma se referia a nota d'aquele Juiz Distrital em data de 25 de Setembro de 1899 dirigida a este consulado sobre o mesmo assunto. Tendo, pois, a honra de dirigir-me à V.S. para pedir-vos que vos digneis providenciar afim de que da competente autoridade seja remetida a este consulado a dita rapariga.

No mesmo dia, a menor foi removida da guarda de seu tutor, entregue ao Consulado do Reino da Itália em Porto Alegre e encaminhada para seu país de origem. Com esse processo, podemos perceber algo que não consta nos relatórios consulares estudados por Luiza Iotti (2001): a participação direta do Estado italiano, por meio de seu diplomata, na guarda de uma menina italiana, demonstrando que o próprio Estado italiano não estava somente materializando "[...] os interesses da classe dirigente italiana em relação à emigração e aos emigrantes” (IOT'TI, 2001, p. 110), mas também se preocupando com as crianças e os adolescentes que, pelas vicissitudes da vida no além mar, pudessem estar passando por dissolução familiar. Mas o caso da menor Maria Marini não fora o único.

\section{A família Sigandi}

Margarida, Rosa, Celestina e João Sigandi ${ }^{10}$, todos irmãos, com doze, dez, seis e dois anos e meio, respectivamente, foram apresentados ao Juízo dos Órfãos de Porto Alegre em oito de março de 1889, dez anos antes da data em que viria a ocorrer o processo de que tratamos anteriormente.

Quem abriu o processo de tutela foi o Juiz de Órfãos Dr. Bernardo Dias de Castro Sobrinho que foi informado que haviam falecido "[...] nesta cidade um casal de colonos, marido e mulher, deixando quatro filhos [...]" (RIO GRANDE DO SUL, 1889, s. p.), filhos de Pedro Sigandi, falecido, (que, na verdade, morreu em seu país natal) e de Josepha Decane, que havia falecido de "febre

Anos 90, Porto Alegre, v. 20, n. 38, p. 273-293, dez. 2013 
amarela" no mesmo mês e ano da abertura dos autos. Dessa forma, para não deixar nenhum dos irmãos desamparados, a Justiça deu novos responsáveis para os quatro irmãos: João José do Amaral, para a menina Margarida; Pedro Theobaldo Jaeger, para a menor Rosa; Ernesto Theobaldo Jaeger, para Celestina e Manuel da Silva Teixeira, ao pequeno João, de dois anos e meio.

No dia onze, o Escrivão Capitão Sebastião Lins de Azambuja notificou todos os tutores da decisão do Juiz, contudo somente Ernesto Theobaldo Jaeger veio, no dia treze, "na casa da residência do senhor Doutor Juiz de Órfãos" e assinou o "Juramento de tutor" da menor Celestina "[...] de seis anos de idade e órfã de pai e mãe, curando de sua pessoa e provendo todos seus interesses tanto em Juízo como fora dele" (RIO GRANDE DO SUL, 1889, s. p.). Quanto aos outros irmãos, não sabemos o que ocorrera até o três de fevereiro de 1891.

Dois anos depois de receber a guarda da menor Celestina, Ernesto Jaeger voltou ao Juízo dos Órfãos informando que era tutor nomeado pela Justiça da menina Celestina, irmã de outros três menores, órfã de pai e mãe, mas que ela havia sido retirada de sua guarda.

Informava também que os quatro, com o falecimento dos pais, haviam ficado "na mais extrema miséria, sem a mínima proteção" e que haviam sido apresentados a ele pelo Chefe de Polícia Dr. José de Azevedo e Silva, que, "[...] condoído pelo estado em que eles se achavam", pedira a ele que "[...] tomasse conta deles dando-lhes, se possível fosse, arrumação de modo a não mais continuarem em tal estado". Atendendo "de boa vontade" (RIO GRANDE DO SUL, 1889, s. p.), Ernesto Jaeger separou os quatro irmãos entre os quatro indicados para tutores dos menores, lembrando, possivelmente ao Juiz, que ele informara ao Juizado de Órfãos a situação de vulnerabilidade em que se encontravam os menores, demonstrando, desde o início de sua "fala", que estava diretamente interessado no futuro das crianças, mesmo que, embora tivessem todos sido nomeados tutores dos menores, somente ele havia assinado o termo de compromisso.

Contudo, o motivo que o levara a reabrir o processo de tutela dos menores da família Sigandi foi que: 
Decorrido mais de um ano, quando o supl. e sua esposa já consagravam sincera amizade a sua tutelada, eis que o governo italiano, ciente do falecimento daqueles imigrantes reclamou ditos órfãos, que sendo entregues no respectivo Cônsul, seguiram para a Europa em abril do ano p. findo, apesar do bom tratamento e esmerada educação que recebia daqueles cidadãos, como bem informou a Chefatura de Polícia ao referido Cônsul, em oficio n ${ }^{\circ} 71$ de 23 de janeiro do citado ano." (RIO GRANDE DO SUL, 1889, s. p.).

Ou seja, novamente o governo italiano, sabendo que uma família de italianos havia sido dissolvida pela morte do marido e da esposa, atuou no sentido de proteger a prole que porventura houvesse da relação, nesse caso, juntando os quatro irmãos e os enviando para a Europa.

Entretanto, esse não foi o motivo primordial da reabertura do auto de tutela. O fato que chama a atenção é que os menores, diferentemente do que se observa no processo anterior (o da menina Maria Marini, que fora enviada para a Itália e lá fora viver com seu tio), os menores da família Sigandi voltaram do "Velho Continente" e foram entregues a Manuel da Silva Ferreira, que entregou a menina Celestina a Felix Ferreira de Mattos, o qual não queria devolvê-la ao seu tutor. Assim, Ernesto Jaeger retornava ao judiciário solicitando a volta da menor para sua guarda, pois ainda era o seu tutor.

Interessante perceber que o tutor não havia questionado a retirada da menor pelos agentes do Consulado Italiano, em onze de abril de 1890, pois reconhecia a ação do Estado (ou pelo menos era impotente frente a ela), mas, quando soubera da volta da menor em dezembro do mesmo ano, não se conformara que ela não voltara para sua guarda e, então, reingressara no Juízo dos Órfãos solicitando a volta da menina Celestina aos seus cuidados.

No mesmo dia, o Juiz Antonio Antunes Ribas mandou que a menor fosse apresentada em vinte e quatro horas, à Justiça. Ainda no mesmo dia, o Oficial de Justiça José Dias da Rosa informava que havia intimando Felix Ferreira de Mattos. Este, no dia seguinte, compareceu ao Juízo dos Órfãos informando que a menor não se encontrava com ele, pois a havia devolvido a Manoel da Silva Fer- 
reira, que era o responsável por ela e seus irmãos "pelos parentes mais próximos destes menores na Itália”. Feito o devido esclarecimento, Felix Mattos foi liberado pelo Juiz.

Inconformado com a notícia de que, ao acabar o prazo de vinte e quatro horas para a apresentação da menor ao Juiz, Felix Mattos havia devolvido a menor Celestina para Manoel Ferreira, Ernesto Jaeger vinha requerer " [...] a expedição de novo mandado para apresentação incontinente ou apreensão da referida menor em poder de Ferreira ou de quem quer que seja que a tenha ilegalmente". O tutor usava todo o respaldo que a lei orfanológica lhe dava para ter sua tutelada de volta à sua guarda.

No mesmo dia, o Juiz expediu mandando que fosse cumprido pelo Oficial de Justiça João Baptista de Araújo. Contudo, no dia seis do mesmo mês, foram anexados dois documentos que dirimiriam todas as intenções e chances que Ernesto Jaeger tinha para reaver a guarda da pequena Celestina, de apenas seis anos de idade.

Em papel timbrado, em que se lê: "Secretaria do Interior Diretoria" e "Palácio do Governo em Porto Alegre", o General Candido Cortez informava ao Juiz de Órfão que:

Ao Sr. Dr. Juiz de Direito da $2^{a}$ Vara ${ }^{11}$ desta capital: No incluso ofício de 4 do corrente mês representa o Cônsul da Itália nesta Capital sobre o fato de haver sido intimando por esse Juízo o cidadão Felix Ferreira de Mattos para entregar uma menor, órfã, de nome Celestina Sigandi, a Ernesto Theobaldo Jaeger, que se diz dela tutor. Dos documentos anexos ao referido oficio, e que oportunamente devolvereis, vê-se que a dita menor e seus irmãos Rosa e João Sigandi12 foram, de ordem do Ministério das Relações Exteriores da Itália, daqui remetidos pelo Consulado da Itália para aquele país e dali remetidos com assentimento de seus parentes para serem entregues nesta Capital a Manoel da Silva Ferreira, com a obrigação de tratar dos mesmos menores, criá-los e educá-los como seus próprios filhos, tendo sido entregue a menor Celestina, por consentimento de Ferreira, aos cuidados do cidadão Felix de Mattos. Ficando, portanto sem efeito, com a repatriação da menor Celestina, a tutoria exercida por Er- 
nesto Theobaldo Jaeger, envio-vos, para os fins de direito, a representação do Cônsul da Italiano [sic] os documentos que a acompanham.” (RIO GRANDE DO SUL, 1889, s. p.).

Por meio desse longo ofício, podemos perceber duas situações: primeiro, a da confirmação da ação de Manuel Ferreira e Felix Mattos de entrarem em contato com o Consulado Italiano, para que este interviesse na contestação da guarda da menor Celestina por eles; e a segunda, a de que novamente o Consulado agira de forma direta na ausência do pai e da mãe de crianças e adolescentes filhos ou descendentes de italianos no Rio Grande do Sul, removendo as crianças do seu tutor legal, enviando-as para a Europa, trazendo-as de volta e distribuindo-as para outro responsável, com o embasamento de que haviam sido "repatriadas", tendo sempre o amparo das autoridades nacionais e estaduais para suas ações, pois os ofícios iniciais eram remetidos diretamente ao Governador do Estado.

O Cônsul Marefoschi Mario Compagnoni, que atuou em Porto Alegre de 27 de maio de 1888 a 20 de maio de 1891, enviou ofício ao então Governador do Estado, Júlio de Castilhos, pedindo que interferisse na situação; para tanto, informava que a menor Celestina havia sido enviada, em onze de abril de 1890, juntamente com seus irmãos, "por ordem do Ministério das Relações Exteriores do Reino da Itália”, a parentes próximos na Itália, mas que estes, na condição de camponeses, haviam apresentado documento em anexo, no qual declaravam renunciar a toda a responsabilidade, pois não podiam ficar com os menores; assim, entregaram os menores a Manoel da Silva Ferreira, que "[...] fez as despesas da viagem e teve consentimento dos parentes mais próximos dos ditos menores de tratar de seu futuro" (RIO GRANDE DO SUL, 1889 , s. p.) conforme prometera "em carta ao Syndico da Villa de Rosasco, na província de Pavia". Acrescentou o Cônsul que "[...] os parentes destas crianças renunciaram ao direito de fazê-los voltar para pátria sem o consentimento do mesmo Sr. Ferreira, considerado por eles como pai adotivo dos ditos órfãos" (RIO GRANDE DO SUL, 1889, s. p.) concluindo seu ofício da seguinte forma: 
Ora, tendo esta menina com seus irmãos seguido [sic] para Itália, em cumprimento de ordens de meu governo, é instintivo que cessou com a partida deles todos e qualquer ato de tutela anterior, não só em relação a menor Celestina da qual se diz tutor o Snr. Jaeger, assim também com seus irmãos Rosa e João Sigandi, que não tinham tutores, e estavam em companhia de Pedro Jaeger e Ferreira. Exposto assim os fatos V. Exc. no seu alto espírito de equidade veras ser incompatível a anterior tutela do Snr. Ernesto Jaeger com o ato publico aqui junto, que confere toda a responsabilidade de criar e educar os menores, ao Snr. Manoel da Silva Ferreira. Por conseguinte espero que V. Ex. providenciara [sic] neste sentido para o respeito da vontade dos mais próximos parentes dos menores. Aproveito a oportunidade, Snr. Governador, para apresentar-vos os protestos da minha estima e subida consideração." (RIO GRANDE DO SUL, 1889, s. p.).

Depois desse ofício, juntamente com os documentos que chancelavam a veracidade das informações do Cônsul italiano Marefoschi Mario Compagnoni, não foi dada continuidade ao processo, tendo este sido arquivado.

Por meio desses dois processos envolvendo as famílias Marini e Sigandi, foi-nos possibilitado o descortínio de um outro viés no que diz respeito à atuação do Consulado Italiano em Porto Alegre: o cuidado do Estado italiano para com seus "súditos". As decisões tomadas por esse órgão revelam não somente preocupação com aspectos econômicos ou de colonização, mas também sensibilidade diante das dificuldades que seus conterrâneos estavam a enfrentar no Estado mais meridional do Brasil, principalmente as crianças e os adolescentes.

As vicissitudes que o "país da fartura" muitas vezes apresentava:

[...] na roça ou nomeio do mato, na forma de cobras e insetos que picavam os indivíduos que lidavam nas tarefas agrícolas, levando muitas vezes ao óbito. [...] A desestruturação da família podia ocorrer devido às doenças e às epidemias que faziam parte do cotidiano dessa população de imigrantes. As más condições de habitação, alimentação e higiene 
contribuíram para o aumento de casos em que as crianças viam-se privadas da presença materna ou paterna, ou de ambos (SCOTT; BASSANEZI, 2005, p. 169).

Mesmo assim, podemos visualizar a atuação do Estado italiano, por meio de seus cônsules, que intervinham diretamente na recolocação de crianças e adolescentes filhos ou descendentes de italianos para junto de seus familiares no Velho Continente.

\section{Considerações finais}

Ao finalizar este texto, cabe levantar: por que a atuação do Consulado Italiano de Porto Alegre nos processos de tutela do Juízo dos Órfãos não ficou expressa nos relatórios enviados para o Ministério dos Negócios Exteriores do Reino da Itália? Ainda não temos condições de responder de forma satisfatória. Talvez os autos fossem situações atípicas, casos excepcionais, ou será pela lógica da fonte? Assuntos e temas relacionados à e/imigração que fossem de interesse imediato para o Reino da Itália eram redigidos, mas temas pontuais, como a orfandade de crianças de origem ou descendência italiana, possivelmente não. Mesmo assim, o Estado italiano operou de forma decisiva no destino de alguns menores de idade, como nos dois processos judiciais analisados para os anos finais do século XIX na cidade de Porto Alegre.

Os autos de tutela permitem apresentar agentes históricos que, muitas vezes, estão silenciados pela "falta de fontes". Tendo em mente que os processos judiciais não foram produzidos com a finalidade de se tornarem fontes para o Historiador (BACELLAR, 2011), os processos de tutela podem se tornar documentos de investigação privilegiados para a História Social, principalmente para aqueles que têm a temática da família, da criança e do adolescente, bem como da e/imigração como alvo (CARDOZO, 2010).

Estudar a temática da e/imigração passa necessariamente pelo viés da família; sendo assim, não podemos negligenciar as pequenas peças que ajudam a completar o grande mosaico que foi a imigração italiana para o Rio Grande do Sul. Ao privilegiar esses dois 
processos, em que pese a forte atuação do Consulado Italiano neles, ambicionamos desvelar a possibilidade da ação estatal italiana na formação de novos arranjos familiares, bem como o foco central das ações que eram o bem-estar dos menores. No primeiro caso, a menor órfã Maria Marini foi enviada para a companhia de seu tio na Itália, depois de ter sido tutelada pelo senhor Luiz Candido de Albuquerque; no segundo, os irmãos, antes separados com a morte dos pais, foram enviados de volta para junto de parentes próximos no Velho Continente, mas estes, devido às dificuldades de subsistência (ou porque não os reconheciam como parentes, ou mesmo porque não queriam ter os menores consigo), não aceitaram a guarda desses pequenos que, diferentemente do que ocorreu no caso anterior, foram trazidos de volta para Porto Alegre e dados novamente à tutela.

Essas crianças circulavam de "responsável em responsável". A circulação de crianças é um conceito antropológico fundamental para a compreensão dos processos de tutela produzidos pelo Juízo dos Órfãos, pois representa a transferência temporária e/ou definitiva de um menor de sua família biológica para terceiros, pertencentes ao grupo sanguíneo ou não (FONSECA, 2006). Esses pequenos atores sociais muitas vezes estavam inseridos em situações completamente desesperadoras, como o abandono, ou mesmo, como nos casos anteriormente expostos, haviam sido afligidos pela fatalidade da morte, e o Estado brasileiro, por meio do Juízo dos Órfãos, procurava inseri-los em novos arranjos familiares, para não os deixar desamparados. Assim também o Consulado Italiano intervinha junto aos filhos de italianos e seus parentes próximos, mesmo que isso significasse retirá-los da guarda de um adulto para entregá-los a outros.

Os casos apresentados aqui, que compõem mais de seiscentos processos de tutela produzidos entre 1860 e 1899 para a cidade de Porto Alegre, destacam a grande importância que os Estados, tanto o brasileiro quanto o italiano, davam aos menores de idade e revelam a ponta de um gigantesco iceberg que, metaforicamente, é o conjunto processual produzido pela Justiça por meio do Juízo dos Órfãos. Assim, através dessa documentação, podemos perceber como a proteção à criança e ao adolescente das famílias italianas e sua descendência era estimada, mesmo que isso não fosse expresso nos relatórios consulares, para a formação da sociedade dos séculos XIX e XX. 


\section{ORFANI ITALIANI IN THE JUÍZO DOS ÓRFÃOS DE PORTO ALEGRE (LATE NINETEENTH CENTURY).}

Abstract: Many children and teens Italians, along with their families, transposed oceanic barriers and came to Rio Grande do Sul in search of better job opportunities and living conditions. However, the events surrounding the majority of the population between the late nineteenth and early twentieth century's, also afflicted families of Italian immigrants, some of which were quite disjointed due to the death of their parents. So many children and adolescents immigrants or descendants also had to live with the orphans. To take care of these children, the Brazilian state owned the Juízo dos Órfãos, the institution of the Judiciary intended to assign an adult as guardian for minor, and the Italian government an instance of legal representation in Brazil - the Italian Consulate. It is the intention of this work, through Social History, presenting some of the smaller Italian and Italian-Brazilians who had their stories recorded in the Tutelage Proceedings of Porto Alegre, which received attention of the Italian Consulate in Porto Alegre in their actions. Thus, reflecting on these foreign minors and analysis to bring children and teenagers who often remain in the background studies e/immigration. Keywords: Orphans. Foreign. Italians. Juízo dos Órfãos.

\section{Notas}

${ }^{1} \mathrm{O}$ termo órfão não deve ser entendido estritamente, pois pode representar menores órfãos de pai e mãe como também os órfãos de pais vivos, ou seja, poderia representar aqueles que tinham seus progenitores vivos.

${ }^{2}$ É necessário esclarecer que, somente depois da Independência do Brasil, com a resolução de 31 de outubro de 1831, é que a idade de 21 anos foi definida como idade limite da menoridade de um filho, ou seja, idade limite do pátrio poder sobre este e que só em 1990, com o Estatuto da Criança e do Adolescente (2007), é que a idade de 18 anos seria fixada como limite da menoridade no Brasil.

${ }^{3}$ Litígio, segundo o dicionário jurídico, é a "[...] demanda, disputa; pendência, contenda... O litígio somente terá início quando a parte contesta o pedido do autor" (SANTOS, 2001, p. 153).

${ }^{4}$ A função de curador dos incapazes ou interditos, como também era chamada, era igual à de tutor de menor (Ord. Fil. liv.4ª , tit. 104 \6).

${ }^{5} \mathrm{O}$ termo Poder Judiciário é utilizado em Portugal após a Constituição, em 1822, e, no Brasil, após a Constituição de 1824.

${ }^{6}$ Mais informações sobre o Juízo dos Órfãos em Porto Alegre, os cargos e as funções dos membros desse juizado, ver: CARDOZO, José Carlos da Silva; 
FLECK, Eliane Cristina Deckmann; SCOTT, Ana Silvia Volpi. O Juízo dos Órfãos em Porto Alegre (prelo).

${ }^{7}$ RIO GRANDE DO SUL. Juízo Districtal da Vara de Orphãos de Porto Alegre. $2^{\text {a }}$ Vara. Tutela. Proc. no 262 de 1899. [manuscrito]. Porto Alegre, 1899. Localização: APERS.

${ }^{8}$ Ato de falar ou tomar ciência do conteúdo de um processo (SANTOS, 2001, p. 246).

${ }^{9}$ Promotor Público do Juízo dos Órfãos, não foi possível identificar o nome do Curador Geral pela assinatura.

${ }^{10}$ RIO GRANDE DO SUL. Juízo Districtal da Vara de Orphãos de Porto Alegre. $3^{\text {a }}$ Vara. Tutela. Proc. $\mathrm{n}^{\circ} 572$ de 1889. [manuscrito]. Porto Alegre, 1889. Localização: APERS.

${ }^{11}$ O processo foi iniciado em 1889, na $2^{a}$ Vara de Órfãos, mas sua continuidade foi dada em 1891, na $3^{\text {a }}$ Vara.

${ }^{12}$ Sobre a menor Margarida, os autos silenciaram. Não conseguimos localizá-la em nenhum outro processo do Juízo dos Órfãos de Porto Alegre.

\section{Referências}

ALMEIDA, Cândido Mendes de. Código Filipino ou Ordenações e leis do Reino de Portugal, recompiladas por mandado do rei D. Philippe I. 14. ed. Rio de Janeiro: Tipografia do Instituto Philomathico, 1870. Disponível em: < http://www1.ci.uc.pt/ihti/ proj/ filipinas/>. Acesso em: 08 out. 2009.

BACELLAR, Carlos de Almeida Prado. Uso e mau uso dos arquivos. In: PINSKI, Carla Bassanezi (Org.). Fontes históricas. 3. ed. São Paulo: Contexto, 2011. p. 23-79.

BLOCH, Marc Leopold Benjamin. A história, os homens e o tempo. In: Apologia da história, ou, o ofício de historiador. Prefácio: LE GOFF, Jacques; Apresentação à edição brasileira, SCHWARCZ, Lilia Mortiz; Tradução de André Telles. Rio de Janeiro: Jorge Zahar (Ed.), 2001. p. 51-68.

CARDOZO, José Carlos da Silva. O Juizado de Órfãos de Porto Alegre e a tutela de menores: a formação do futuro cidadão através do trabalho. Aedos, UFRGS, v. 2, n. 4, p. 146-156, 2009.

. O Juízo dos Órfãos e a organização da família por meio da tutela. História Social, UNICAMP, n. 20, p. 201-220, 2011.

. Órfãos e estrangeiros no Juízo dos Órfãos. Oficina do Historiador, PUCRS, v. 2, n. 1, p. 97-108, 2010. 
; FLECK, Eliane Cristina Deckmann; SCOT'T, Ana Silvia Volpi. O Juízo dos Órfãos em Porto Alegre. Revista Justiça \& História. Tribunal de Justiça do Estado do Rio Grande do Sul, Porto Alegre (prelo).

FAVARO, Cleci Eulalia. Os “italianos": entre a realidade e o discurso. In: PICCOLO, Helga Iracema Landgraf; PADOIN, Maria Medianeira (Dir.). História Geral do Rio Grande do Sul-Império. v. 2. Passo Fundo/RS: Méritos, 2006. p. 301-319. FONSECA, Claudia. Caminhos da adocão. 3. ed. São Paulo: Cortez, 2006.

GIRON, Loraine Slomp. A imigração italiana no RS: fatores determinantes. In: LANDO, Aldair et al (Org.). RS: imigração e colonização. Porto Alegre: Mercado Aberto, 1980, p. 47-66.

IOTTI, Luiza Horn. O olhar do poder a imigração italiana no Rio Grande do Sul, de 1875 a 1914, através dos relatórios consulares. 2. ed. Caxias do Sul: Educs, 2001.

MOURA, Esmeralda Blanco Bolsonaro de. Mulheres e menores no trabalho industrial: os fatores sexo e idade na dinâmica do capital. Petrópolis/RJ: Editora Vozes, 1982. RIO GRANDE DO SUL. Ministério Público. Centro de Apoio Operacional de Infância e da Juventude. Estatuto da criança e do adolescente e legislação pertinente. Porto Alegre: Procuradoria-Geral de Justiça, 2007.

- Juízo Districtal da Vara de Orphãos de Porto Alegre. $2^{\circ}$ Vara. Tutela. Proc.n 262 de 1899. [manuscrito]. Porto Alegre, 1899. Localização: APERS.

- Juízo Districtal da Vara de Orphãos de Porto Alegre. $3^{\circ}$ Vara. Tutela. Proc.n 572 de 1889. [manuscrito]. Porto Alegre, 1889. Localização: APERS.

SANTOS, José Vicente Tavares dos. Cantineiros e colonos: a indústria de vinho no Rio Grande do Sul. In: LANDO, Aldair et al (Org.). RS: imigração e colonização. Porto Alegre: Mercado Aberto, 1980, p. 135-155.

SANTOS, Washington dos. Dicionário jurídico brasileiro. Belo Horizonte: Del Rey, 2001.

SCOTT, Ana Silvia Volpi; BASSANEZI, Maria Silvia C. No fundo do baú: procurando as crianças imigrantes nas fontes documentais paulistas. In: RADIN, José Carlos (Org.). Cultura e identidade italiana no Brasil. Joaçaba/SC: UNOESC, 2005. p. 163-176.

TISOT'T, Ramon Victor. Pequenos trabalhadores: infância e industrialização em Caxias do Sul (Fim do séc. XIX e Início do XX). Dissertação (Mestrado em História), Universidade do Vale do Rio dos Sinos, São Leopoldo, RS, 2008.

Recebido em: 21 de outubro de 2012.

Aprovado em: 11 de abril de 2013.

Anos 90, Porto Alegre, v. 20, n. 38, p. 273-293, dez. 2013 